\title{
Research Paper: Bioinformatics Analysis of Linear B-cell Viscumin Toxin Epitope With Potential Use in Molecularly Imprinted Polymer Biosensors
}

\author{
Sasan Nasirahmadi ${ }^{*}\left(\mathbb{D}\right.$, Jamil Zargan $^{1}(\mathbb{B}$ \\ 1. Department of Biology, Faculty of Basic Science, Imam Hussein University, Tehran, Iran.
}

\begin{tabular}{|c|c|}
\hline 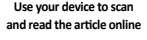 & Citation: Sasan Nasirahmadi, Jamil Zargan. Bioinformatics Analysis of Linear B-cell Viscumin Toxin Epitope With Potential \\
\hline 口田回 & rly Imprinted Polymer Biosensors. International Journal of Medical Toxicology and Forensic Medicine. 2020; \\
\hline 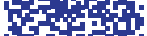 & 10(1):26172. https://doi.org/10.32598/ijmtfm.v10i1.26172 \\
\hline tas & doij https://doi.org/10.32598/ijmtfm.v10i1.26172 \\
\hline
\end{tabular}

\section{(c) (i) (s)}

Article info:

Received: 10 Jul 2019

First Revision: 25 July 2019

Accepted: 23 Dec 2019

Published: 16 Feb 2020

\section{A BSTRACT}

Background: There are many diseases around the world that threaten human health and its related hygienic issues. Cancer is among the conditions mentioned above that cause many problems for health sectors worldwide.

Methods: The present research analyzed the linear B-cell epitope of viscumin from European mistletoe using bioinformatics tools. We also provided references for the fast detection of biological agents. Several important tools, such as Protparam, NCBI, PDB, T-coffee, BCpred, Bptope, Ellipro, and Cn3D were used to predict the viscumin linear epitope and its physical and chemical properties.

Results: The 9-mer epitope found as QQTTGEEYF embedded in the A-chain of protein by the least sequence homology with other homologous rivals. Its molecular weight, theoretical isoelectric point, and the total number of negatively charged residues were 1102.1, 3.79, and 2 , respectively.

Conclusion: Using different databases and establishing the accuracy level of $>50 \%$ for linear B-cell epitope prediction, the selected epitope passed the related criteria and was introduced as a new linear epitope as a potential biological element in biosensors for cancer (viscumin) fast therapeutic detection. tion methods, which include conventional or laborious attitude, might be time-consuming; these steps may pass the process of target bio-analyte cultivation at a desired circumstance as well as checking the quality of final products out. Although traditional methods work, but they include unfavorable drawbacks as being laborious, time-consuming, dependent to skillful experts, lead to (0xic protins $[1,2]$. The trational detec-

* Corresponding Author:

Sasan Nasirahmadi, PhD Candidate.

Address: Department of Biology, Faculty of Basic Science, Imam Hussein University, Tehran, Iran.

Tel: +98 (911) 2152985

E-mail: s.nasirahmadi@gmail.com 
killing the time which may result in even pandemic situations or vast mortality [3-6].

Viscumin as an important cytotoxin due to its pharmacological effects extracted from mistletoe extracts are discussed in detail by the concentration of three toxic lectins: mistletoe lectin I (MLI, or viscumin), MLII, MLIII by Tonevitsky and co-workers. These proteins, as well as ricin, belong to ribosome-inactivating proteins type 2 (RIP2). The causes of the differences in activity of plant toxins as pharmacological agents, and the importance of above mentioned epitopes for neutralizing antibodies at the clinical applications of mistletoe extracts are discussed [7].

Regarding the importance of detection of the toxin in clinical and forensic medicine, it is worthy to notify that ribosome inactivating proteins (RIPs) are highly potent cytotoxins that have potential as anticancer therapeutics. Mistletoe lectin 1 (ML1) is a heterodimeric cytotoxic protein isolated from European Mistletoe and belongs to RIP class II. The aim of Beztsinna and his co-workers was to systematically study ML1 cell binding, endocytosis pathway(s), subcellular processing and apoptosis activation. Additionally, co-localization studies by aforementioned researchers demonstrated the toxin transport from early endocytic vesicles to Golgi network; a retrograde road to the endoplasmic reticulum. The proapoptotic and anti-proliferative activity of ML1 were shown in time lapse movies and subsequently quantified. ML1 cytotoxicity was less affected in multidrug resistant tumor cell line 4T1 in contrast to commonly used chemotherapeutic drug (ML1 resistance index 6.9 vs. 13.4 for doxorubicin; IC50: ML1 $1.4 \mathrm{ng} / \mathrm{ml}$ vs. doxorubicin $24000 \mathrm{ng} / \mathrm{ml}$ ). This opens new opportunities for the use of ML1 as an alternative treatment in multidrug resistant cancers [8].

Bioinformatics is a scientific field where different majors such as computing, biology and information technology come to gather in order to handle and arrange derived biological information in biotechnology, genetics and molecular biology [9]. Also, bioinformatics tools for fast detection field may lead to new concepts for in silico determination of biological receptors in biosensors against dangerous bio-analysts [10].

This study is aimed at providing a route using bioinformatics and its selected software as well as databases for B-cell linear epitope prediction based on the authors personal experiments, and digging in the literature and web databases, providing an outlook on how bioinformatics may shed a helpful light especially on the epit- ope prediction field. The main goal of the present study was to predict an epitope by potential application for a biosensor especially MIP-based one for mistletoe lectin 1 (ML1) or Viscumin- a plant derived therapeutic drugfast detection.

\section{Materials and Methods}

The amino acids arrangement of ML1 was gotten from NCBI at https://www.ncbi.nlm.nih.gov/ the physiological and biochemical characters were anticipated in view of http://web.expacy.org/protparam/, the optional and 3D structure was anticipated, using the National Center for Biotechnology Information (NCBI) and Protein Data Bank (PDB) information server utilizing Cn3D 4.3 from the United States National Library of Medicine that acts as a helper application for web browsers to view threedimensional structures from The National Center for Biotechnology Information's Entrez retrieval service. The direct (constant) B-cell epitope was anticipated in light of different arrangement utilizing T-Coffee online server. Additionally, a few online web-based databases were connected for looking through the epitope areas percent of forecast with adequate precision: BCpred, Bptope, Ellipro, and so on. All sequences extracted from NCBI unless otherwise stated.

\section{Results and Discussion}

\section{Analysis of amino acids sequences}

The accession number of amino acids of Viscumin was UniProtKB/Swiss-Prot: P81446 and its 3D structure number in PDB is 2RG9. At first, its full length amino acid sequence was derived and evaluated for extraction of B-cell epitope (Figure 1).

\section{Structure of Viscumin}

The 3-D structure of Viscumin simulated with online $\mathrm{Cn} 3 \mathrm{D}$ software and the result is depicted in Figure 2.

\section{Predicting B-cell epitope}

At first, four types of protein-type toxins of type $A B$ were extracted and examined. The sequences were obtained from the FASTA format at www.ncbi.nlm.nih.gov .Then, to compare their sequences and to examine their different regions; multiple sequence alignment was applied in order to find an epitope candidate. The result of the comparison of sequences in the T-coffee database is depicted in Figure 3. The result showed that 9-mer ami- 


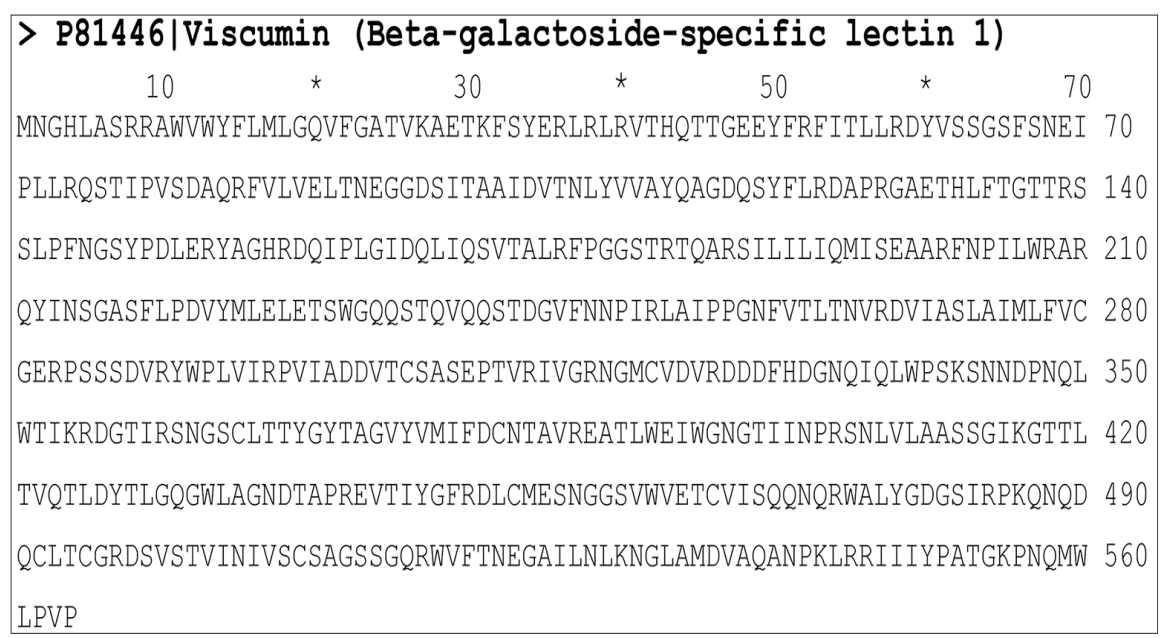

International Journal of
Medical Toxicology \& forensic Medicine

Figure 1. The full-length amino acid sequence of viscumin adapted from NCBI: available in free access

no acid segment highlighted in red (Figure 3) was the best choice to be used in follow.

After analyzing and comparing the different parts of the nine-segment C-terminal peptide sequences of the catalytic toxic chain of Viscumin with the least possible interference, QQTTGEEYF was selected for further investigation, which is depicted in red with black arrow (Figure 3).

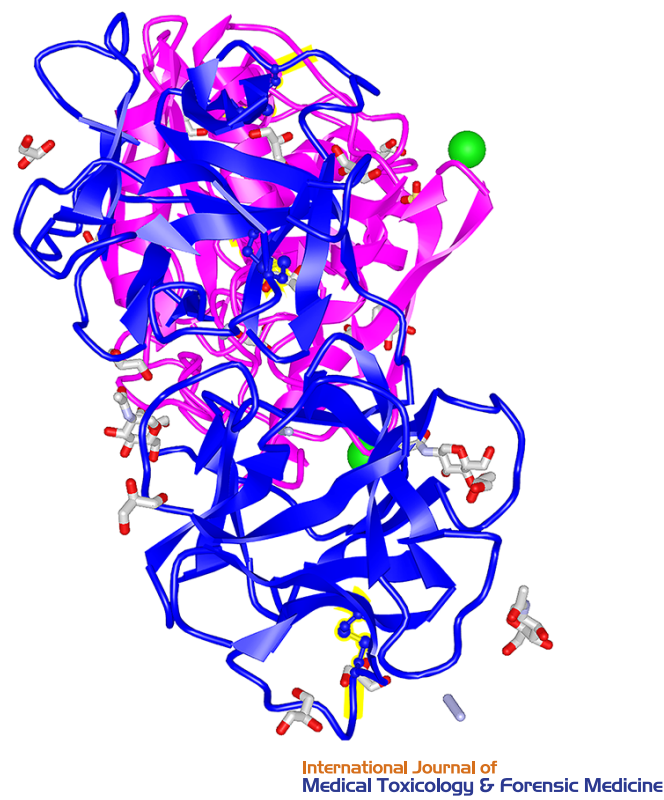

Figure 2. The tertiary structure of viscumin stimulated in online Cn3D software (Yellow lines show disulfide bonds, green ball-type atoms, refer to chloride ions, three-branch structures are, glycerols (15), single capsule-like structure relies on, azide ions (3), four-branch structure depicts sulfate ions (1), and six-branch structures show 4 N-Acetyl-DGlucosamines.
For further and more detailed studies, the isoforms sequences in the data banks of this toxin were examined and multiple aligned to determine the protection of the selected peptide using T-coffee tool (Figure 4).

Multiple alignments of various isomers with Tcoffee

For further and more detailed studies, the isoforms sequences in the data banks of this toxin were examined and multiple aligned to determine the protection of the selected peptide using T-coffee tool (Figure 4). By profound comparison of selected isoforms, it was found that the candidate had a good conservative feature of different isoforms of toxin by multiple sequence alignment. In order to further investigates the sequences of A chain of the toxin in different databases were accomplished with different tools, using the first structure of the protein through the online network software as, Ellipro, BCpred, LPtope, bepitope, SVMTrip, Discotope and CBTOPE (http://www.imtech.res.in/raghava/ cbtope).

The possibility of the presence of the entire selected peptide as an epitope in the relevant sequence was investigated. The results indicated that in all cases, these peptide tools or a large portion of it are predicted to be as epitopes with precision of over $70 \%$ in most cases, and is the only option among other peptides (supplementary data). Thereafter, by referring to the Immune Epitope Database (IEDB) analysis server, epitope conservancy analysis has been accomplished at least in $80 \%$ identity level, but the identity of selected epitope determined more than $85 \%$. Finally, it has been introduced as potential candidates for epitopes. 


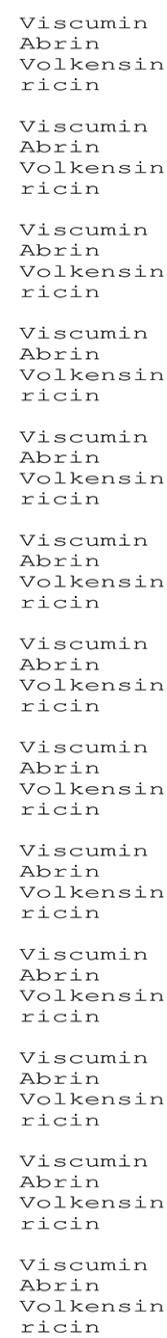

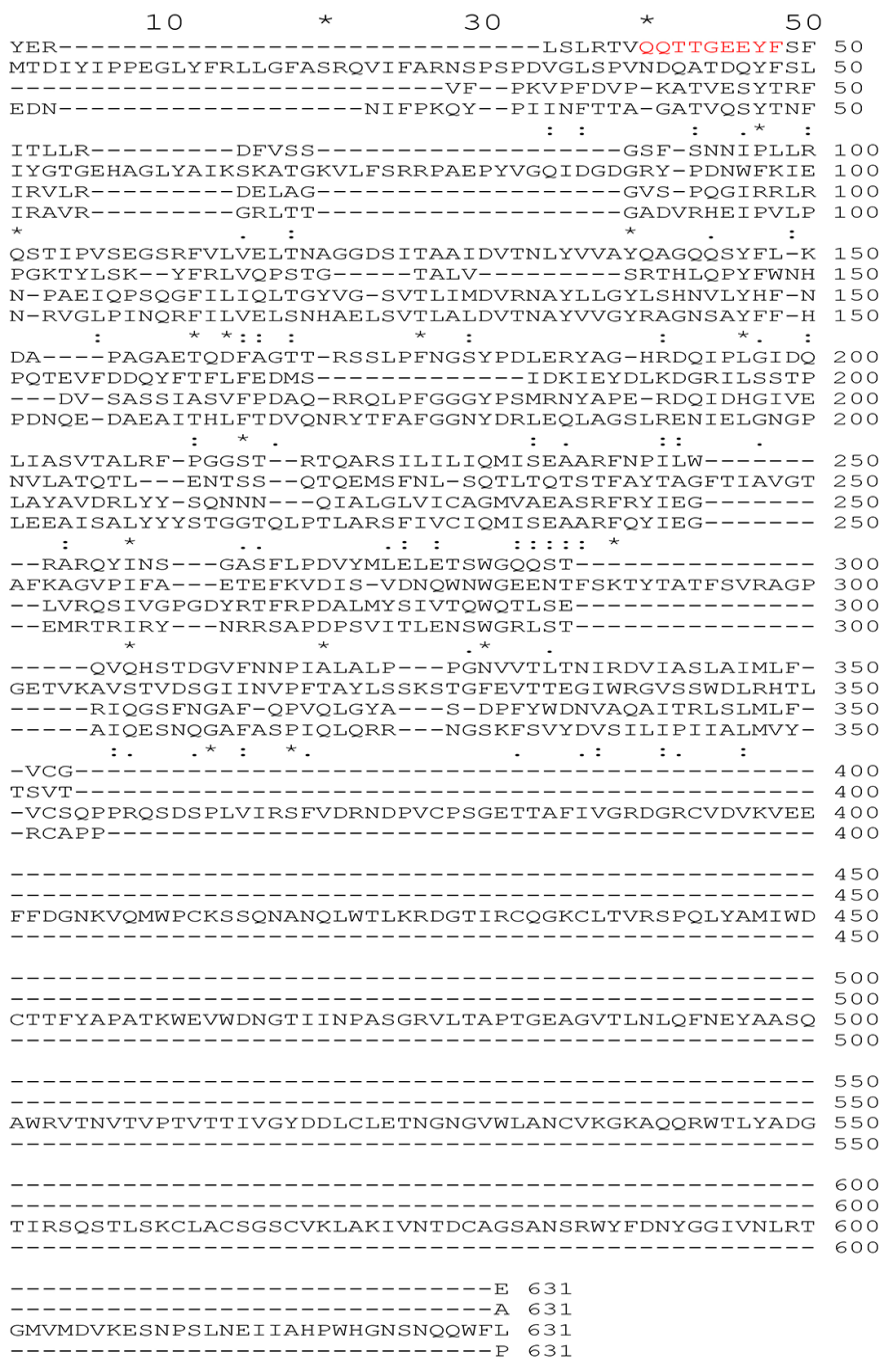

International Journal of Medical Toxicology \& Forensic Medicine

Figure 3. Multiple sequence alignment by T-coffee online server based on CLUSTAL W (1.83)

Thus, it (QQTTGEEYF) was suggested as an epitope for potential use of MIP-based biosensors to solve some aspects of supramolecule challenges such as conformation stability, complexity and mass transfer phenomena. It has also submitted in EMBL-EBI with primary accession number of PRJEB24387 and secondary accession number of ERP106207, but has not yet been released publicly and therefore the full data has been submitted here completely in detail.

The evaluation of nine amino acids steric position, The steric position of selected epitope was determined by Swiss model using Cn3D online software and the result is presented (Figure 5). The full process of steric position of selected epitope is expressed and explained in figure 5. As it can be inferred from Figure 5, the selected 9-mer epitope is exposed on the surface. In addition, the chemical and physical characteristics of selected epitope were recorded by using protparam software placed in expasy complex (Figure 6).

The Instability Index (II) is computed to be 48.70 . This classifies the protein as unstable but based on amino acid structure, there is no interfering amino acid for instability, thus it is stable in its matrix. Also, total number of negatively charged residues (acidic) (Asp + Glu) and positively charged residues (basic) (Arg + Lys) are 2 and 0 , respectively.

\section{Discussion}

The epitope prediction for therapeutic goals, especially in Vaccine or detection affairs showed a great potential, nowadays $[11,12]$. B-cell receptors or relative antibodies are recognized by B-cell epitopes in their folded structures. Amino acid properties such as hyro- 

gi|P81446|Viscumin MNGHLASRRAWVWYFLMLGQVFGATVKAETKFSYERLRLRVTHQTTGEEYFREITLIRDYVSSGSFSNEI 70 gi|P81446|Viscumin MNGHLASRRAWVWYFLMLGQVEGATVKAETKFSYERLRLRVTHQTTGEEYFREITLLRDYVSSGSFSNEI 70 gi|P81446|Viscumin MNGHLASRRAWVWYFLMLGQVEGATVKAETKFSYERLRLRVTHQTTGEEYFREITLLRDYVSSGSFSNEI 70 70 gi|2RG9|A chain gilG1931lectin gilG193/ lectin 1 gi|lsz6|A chain gi|P81446|Viscumin gi|2RG9|A chain gi|Gl93|lectin 1 --YERISLRTVQOTTGEEYESEITLLRDFVSSGSFSNNI 70 MNAHLASRRAWVWYFLMICLVFGATVKAETKFSYERLRLRVTHOTTGEEYFREITLIRDYVSSGSFSNEI 70 MNGHLASRRAWVWYFLMLGOVFGATVKAETKFSYERIRLRVTHQTTGEEYFREITLLRDYVSSGSFSNEI 70 MNG - YERLSLRTVEQTTGAEYFSEITLLRDFVSSGSFSNNI
$* * *: * * \ldots: * * * * * * * * * * * * *: * * * * * * *: *$

PLLRQSTIPVSDAQREVLVELTNEGGDSITAAIDVTNLYVVAYQAGDQSYFLRDAPRGAETHLFTGTTRS 140 PLLRQSTIPVSEASRFVLVELTNEGGDSITAA IDVTNLYVVAYQAGQQSYFLKDAPRGAETQDFTGTTRS 140 PLLRQSTIPVSDAQRFVLVELTNQGGDSITAA I DVTNLYVVAYQAGDQSYFLRDAPRGAETHLFTGTTRS 140 PLLRQSTIPVSDTQRFVLVELSNEGGDS ITAA I DVTNLYVVAYQAGNQSYFLRDAPRGAETHLFTGTTRS 140 PLLRQSTIPVSEGSREVLVELTNAGGDSITAAIDVTNLYVVAYQAGQQSYELKDAPAGAETQDFAGTTRS 140

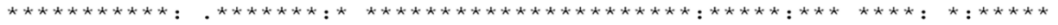

gi|P81446|Viscumin gil2RG9|A chain gi|Gl93|lectin 1 gi|Gl95|lectin gillsz6|A chain

SLPFNGSYPDLERYAGHRDQIPLGIDQLIQSVTALRFPGGSTRTQARSILILIOMISEAARFNPILWRAR 210 SLPFNGSYPDLERYAGHRDQIPLGIDQLIQSVTALRFPGGSTRTQARSIIILIQMISEAARFNPILWRAR 210 SLPFNGS Y PDLERYAGHRDQI PLGIDQLIQSVTALRFPGGSTRTQARSI I ILVQMISEAARFNPILWRAR 210 PLPFNGSYPDLERYAGHRDQIPLGIDQLIQSVTALRFPGGSTRTQARSIIILVQMISEAARENPILWRLR 210 SLPFNGSYPDLERYAGHRDQI PLGIDQLIASVTALRFPGGSTRTQARSILILIQMISEAARFNPILWRAR 210

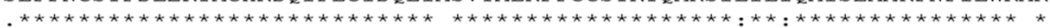

Gi|P81446|Viscumin RFNPILWRARQYINSGASFLPDVYMLELETSWGQQSTQVOQSTDGVFNNPIRLAIPPGNFVTLTNVRDVI 280 QYINSGASELPDVYMUELETSWGQQSTQVQHSTDGVENNPQYINSGASFLPDMYMLELETSWGQQSTQVQ 280 gi|2RG gi|Gl93|lectin gi|Gl95|lectin gi|1Sz6|A chain QYINSGASF LPDVYMLELETSWGQQSTQVQHSTDGVFNNPQYINSGASFLPDMYMLELETSWGQQSTQVQ 280 QYINSGASFL PDMYMLELETSWGQQSTQVQQSTDGVFNNPIRLAIPPGNFVTLTNVRDVIASLAIMLFVC 28 IRLAIPPGNFVTLTNVRDVIASLAIMLEVCGERPSSSDVRYWPLVIRPVIADDVTCSASEPTVRIVGRNG 280 QYINSGASFLPDVYMLELETSWGQQSTQVQHSTDGVFNNPIALALPPGNVVTLTNIRDVIASLAIMLEVC 280

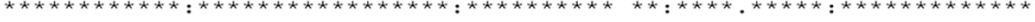
gi|P81446|Viscumin ASLAIMLFVCGERPSSSDVRYWPLVIRPVIADDVTCSASEPTVRIVGRNGMCVDVRDDDFHDGNQIQLWP 350 gi|2RG9|A chain gi|Gl93|lectin gilG1951 lectin 100 gi|lsz6|A chain IRLALPPGNVVTLTNIRDVIAS LAIMLFVCGE-- - - - - QSTDGVFNNPGERPSSSDVRYWPLVIRPVIADDVTCSASEPTVRIVGRNGMCVDVRDDDFHDGNQIQLWP 350 MCVDVRDDDFHDGNQIQLWPSKSNNDPNQLWTIKRDGTIRSNGSCLTTYGYTAGVYVMIFDCNTAVREAT 350 GE-

gi|P81446|Viscumin SKSNNDPNQLWTIKRDGTIRSNGSCLTTYGYTAGVYVMIFDCNTAVREATLWEIWGNGTIINPRSNLVLA 420 gi|2RG9|A chain gi|Gl93|lectin 1 gi|Gl95|lectin 1 gi|1Sz6|A chain SKSNNDPNQLWT IKRDGTIRSNGSCLTTYGYTAGVYVMI FDCNTAVREATIWQIWGNGTI INPRSNLVLA 420 LWEIWGNGTI INPRSNLVLAASSGIKGTTLTVQTLDYTLGQGWLAGNDTAPREVTIYGERDLCMESNGGS 420 - - - - - - -

gi|P81446|Viscumin gi|2RG9|A chain gi|Gl93|lectin 1 gi|Gl95|lectin 1 gi|1Sz6|A chain

gi|P81446|Viscumin gi|2RG9|A chain gi|Gl93|lectin 1 gilG195। lectin gi|lsz6|A chain

gi|P81446|Viscumin PATGKPNQMWLPVP 574 gi|2RG9|A chain gi|Gl93|lectin gi|Gl95|lectin gi|1sz6|A chain

\begin{tabular}{|c|c|}
\hline 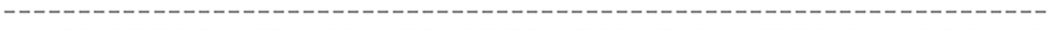 & 490 \\
\hline SGIKGTTLTVQTLDYTLGQGWLAGNDTAPREVTIYGERDLCMESNGGSVWVETCVSSQQNQRWALYGD & 490 \\
\hline VWVETCVISQQNQRWALYGDGSIRPKQNQDQCLTCGRDSVSTVINIVSCSAGSSGQRWVFTNEGAILNLK & 490 \\
\hline & 490 \\
\hline GSIRPKQNQDQCLTCGRDSVSTVINIVSCSAGSSGQRWVFTNEGAILNLKNGLAMDVAQANPKLRRIIIY & 560 \\
\hline - ---- & 560 \\
\hline GSIRPKQNQDQCLTCGRDSVSTVINIVSCSAGSSGQRWVFTNEGAILNLKNGLAMDVAQANPKLRRI I IY & 560 \\
\hline NGLAMDVAQANPKLRRIIIYPATGKPNQMWLPVP & 524 \\
\hline----------------1 & 560 \\
\hline PATGKPNQMWLPVP 574 & \\
\hline 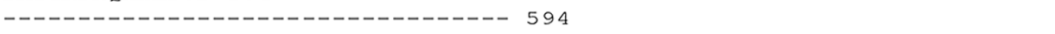 & \\
\hline $\begin{array}{l}\text { PATGKPNQMWLPVP } 574 \\
524\end{array}$ & \\
\hline
\end{tabular}

Figure 4. Multiple alignments of protein isoforms: gi|P81446 |Viscumin; gi|2RC9|A chain; gi|C193 |lectin 1; gi|C195|l and gi|1SZ6|A chain involve; 564, 249, 564, 564 and 249 amino acids, respectively

philicity, charge, exposed surface area and secondary structure have important roles which result in continuous B-cell epitope prediction. On the other hand, 3D structure of the antigen is the basic prerequisite for Bcell epitope prediction in the batch mood [13-15]. To date, in order to predict linear B-cell epitopes, several servers and tools exist. The BCPREDS tool is a simple choice that is emerging and its accuracy is more than $50 \%$ [16]. The next one is the ABCpred server with more than $65 \%$ accuracy [11].

Bepipred is another server, which infers hidden Markov model and a propensity scale method to predict the location of linear B-cell epitopes [17]. In addition, by applying protein antigen's 3-D structure, a new and more powerful tool is essential to predict linear epit- opes in contrast with other aforementioned tools defined as Ellipro. It devotes predicted epitope with a score. Based on homology modeling, a 3-D structure will be predicted for the input sequence. By the emergence of highly dangerous biological agents both with natural and genetically modified (recombinant) source imposed human community for development of more effective approaches to confront the dangerous supramolecule fast detection challenges.

The in silico approaches may be addressed by the aforementioned challenges. One of the main contributing roles of B-cell linear epitope is dedicated to molecularly imprinted polymer biosensors. The achievement in MIP-based biosensors synthesis and development return to the molecular weight of target analyte, which 


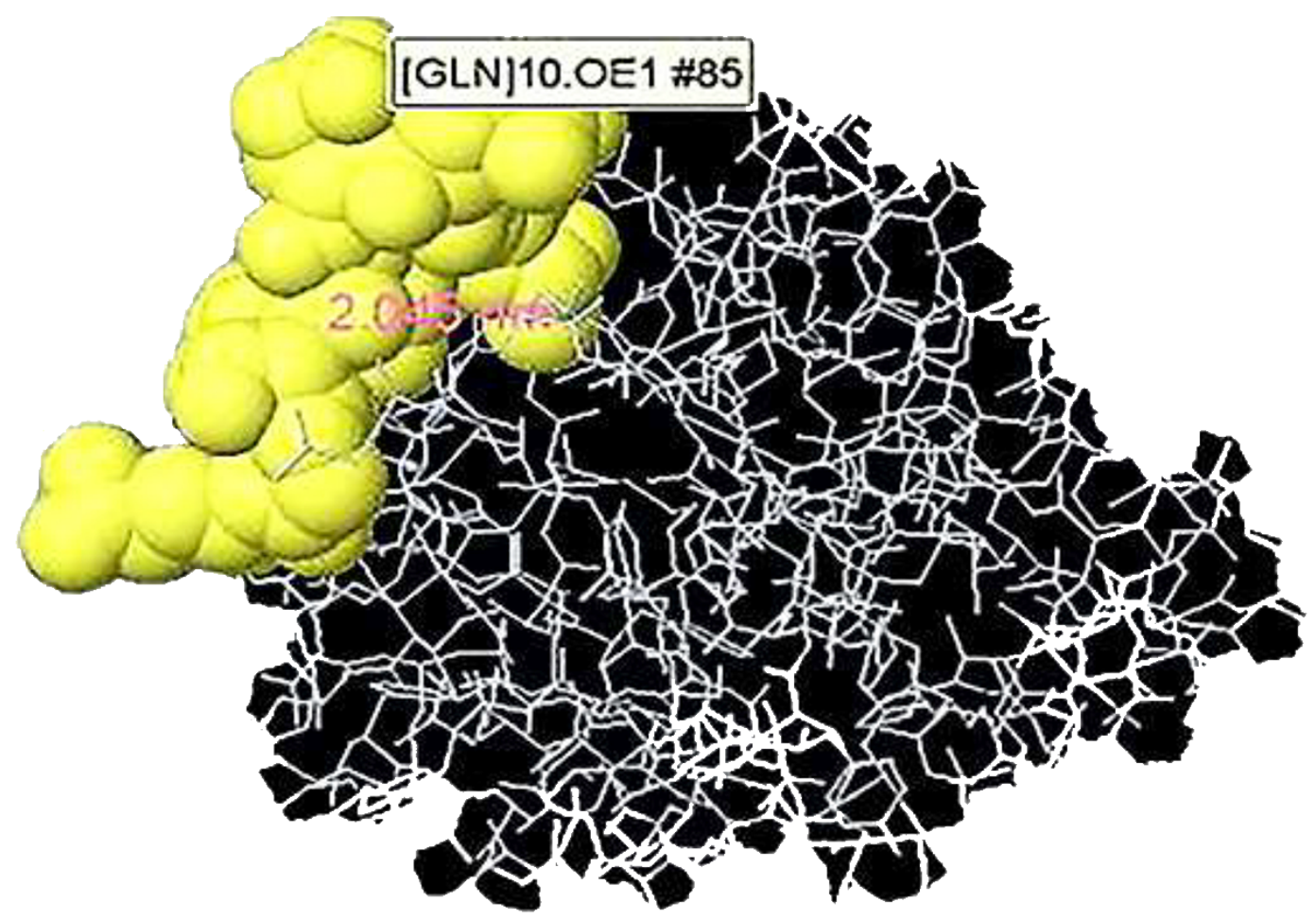

International Journal of
Medical Toxicology \& Forensic Medicine

Figure 5. Steric position of selected epitope obtained with average horizontal width of $2 \mathrm{~nm}$ using online Cn3D software depicted with dense spheres at the top left corner.

is suggested being lower than $5 \mathrm{kDa}$. This caution has to be considered seriously, otherwise the chance of having a proper biosensor for practical use in complex media may be out of mind or hardly acceptable. Epitope approach is one of the new methods which proposed to encounter such a problem.

The Molecularly Imprinted Polymers (MIP) considered synthetic analogues for aptamers, antibodies, antigens, enzymes and other biological detection agents. They often offer very good levels of specificity, like their natural competitors, at a lower cost, longer durability and resistance to inappropriate environmental conditions. As a serious rival in the evolutionary path through natural selection processes, fully synthetic MIPs have opened a new hatch to eliminate some of the constraints of natural systems with more sustainability, logical costs, and faster production to humankind.

MIPs have unique features such as high stability, easy preparation and lower logical costs than their natural rivals. In fact, a new era has begun with the advent of this type of biosensors [18-20]. Protein Bovine Hemoglobin was molded onto an array of acrylamide-based

\section{QQTTGEEYF}

Number of amino acids: 9

Molecular weight: 1102.1 Dalt

Theoretical pI: 3.79

Theoretical pI of A-chain: 5.08249 aa

Theoretical pI of B-chain: 4.99263 aa

Formula: $\mathrm{C}_{48} \mathrm{H}_{67} \mathrm{~N}_{11} \mathrm{O}_{19}$, Total number of atoms: 145 , Extinction coefficients: 1490 , Abs $0.1 \%(=1 \mathrm{~g} / \mathrm{l}): 1.352$
Total number of negatively charged residues (acidic) (Asp + Glu): 2

Total number of positively charged residues (basic) (Arg + Lys): 0

Amino acid composition of epitope candidate: Carbon C 48,

Hydrogen H 67, Nitrogen N 11, Oxygen O 19, Sulfur S 0

Aliphatic index: 0.00 and Grand average of hydropathicity (GRAVY): - 1.589

International Journal of

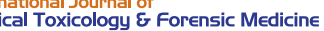

Figure 6. Biochemical characteristic of the selected epitope using protparam software located in NCBI complex 
polymer hydrogels to optimize the piezoelectric sensor electrode surface [21]. In fact, this study was conducted to evaluate the complexity of protein chemistry using monomers. A cancer biomarker called quinogen- a plasma protein- for early diagnosis and cancer prediction was synthesized [22].

Another cancer biomarker, called carcinogenic embryonic carcinogenesis protein, was formed on screening electrodes of polyoxyethylene matrix, which is generally used to monitor the progression of clonal cancer [23]. The epitope-based imprinting could minimize non-specific adsorption, which is a serious problem for protein or macromolecular imprinting. Comparing the epitope with the protein molecule as a template and the formation of a protein epitope sequence, a better result was obtained by the epitope imprinting method [24]. In other research work, 15 amino acid peptides of the Japanese encephalitis virus were imprinted using a new mesenteric monomer capable of differentiating oxytocin and vasopressin [25]. Similarly, a 15 amino acid peptide for detecting yellow fever virus was imprinted as an early alternative diagnostic tool [26].

As it can be inferred, the MIP nanoparticles showed excellent capabilities for the detection of the epitope, such as the HSA protein [27]. Also, another group worked on B-cell epitope prediction and investigated its probability in detail. Although it was a valuable work but the authors did not surveyed some details as isoform alignment and region of conservancy [28]. But in present work, these deficiencies are completely carried out resulted a more powerful prediction with better accuracy. In addition, in other work, several databases were introduced for B-cell epitope prediction $[29,30]$. Some of these suggestions were applied by our group in order to have more powerful prediction but it is not applied by song and his coworker. They only used one of these databases that may not involve a powerful feedback.

\section{Conclusion}

Bioinformatics tools present a favorable opportunity over traditional techniques such as lower costs and more speed in outputs extraction. On the other hand, it has enabled the prediction of potential B-cell epitope (linear) without being concerned to direct contact with dangerous pathogens of interest. In conclusion, suitable B-cell linear epitope involving 9-mer epitope was determined with potential application in fast detection tools especially synthetic ones (molecularly imprinted polymer based biosensors). The in silico selected peptide conservancy was approved successfully and will be tested as a biological element candidate in future work to detect Viscumin applying a surface imprinted polymer based nanobiosensor applying epitope approach.

\section{Ethical Considerations}

\section{Compliance with ethical guidelines}

All ethical principles were considered in this article. The participants were informed about the purpose of the research and its implementation stages; they were also assured about the confidentiality of their information; Moreover, They were allowed to leave the study whenever they wish, and if desired, the results of the research would be available to them.

\section{Funding}

This research did not receive any specific grant from funding agencies in the public, commercial, or not-forprofit sectors.

\section{Author's contributions}

All authors contributed equally in preparing all parts of the research.

\section{Conflict of interest}

The authors declared no conflict of interest.

\section{Acknowledgements}

Authors wish to thank Dr. Abbas Hajizadeh for his benevolence in the bioinformatics study.

\section{References}

[1] Aftabi Y, Colagar AH, Mehrnejad F. An in silico approach to investigate the source of the controversial interpretations about the phenotypic results of the human AhR-gene G1661A polymorphism. Journal of Theoretical Biology. 2016; 393:1-5. [DOI:10.1016/j.jtbi.2016.01.001] [PMID]

[2] Arinaminpathy N, Ratmann O, Koelle K, Epstein SL, Price GE, Viboud C, et al. Impact of cross-protective vaccines on epidemiological and evolutionary dynamics of influenza. Proceedings of the National Academy of Sciences. 2012; 109(8):3173-7. [DOI:10.1073/pnas.1113342109] [PMID] [PMCID]

[3] Beztsinna N, de Matos MB, Walther J, Heyder C, Hildebrandt $\mathrm{E}$, Leneweit $\mathrm{G}$, et al. Quantitative analysis of receptormediated uptake and pro-apoptotic activity of mistletoe lectin-1 by high content imaging. Scientific Reports. 2018; 8:2768 [DOI:10.1038/s41598-018-20915-y] [PMID] [PMCID] 
[4] Bhakta S, Seraji MS, Suib SL, Rusling JF. Antibody-like biorecognition sites for proteins from surface imprinting on nanoparticles. ACS Applied Materials \& Interfaces. 2015; 7(51):28197-206. [DOI:10.1021/acsami.5b11650] [PMID] [PMCID]

[5] Bogdanos DP, Choudhuri K, Vergani D. Molecular mimicry and autoimmune liver disease: Virtuous intentions, malign consequences. Liver. 2001; 21(4):225-32. [DOI:10.1034/j.16000676.2001.021004225.x]

[6] Bossi AM, Sharma PS, Montana L, Zoccatelli G, Laub O, Levi R. Fingerprint-imprinted polymer: Rational selection of peptide epitope templates for the determination of proteins by molecularly imprinted polymers. Analytical Chemistry. 2012 84(9):4036-41. [DOI:10.1021/ac203422r] [PMID]

[7] Cumbo A, Lorber B, Corvini PF, Meier W, Shahgaldian P. A synthetic nanomaterial for virus recognition produced by surface imprinting. Nature Communications. 2013; 4:1503. [DOI:10.1038/ncomms2529] [PMID]

[8] EL-Sharif HF, Aizawa H, Reddy SM. Spectroscopic and Quartz Crystal Microbalance (QCM) characterisation of protein-based MIPs. Sensors and Actuators B. 2015; 206:239-45. [DOI:10.1016/j.snb.2014.09.053]

[9] Greenbaum JA, Andersen PH, Blythe M, Bui HH, Cachau $\mathrm{RE}$, Crowe J, et al. Towards a consensus on datasets and evaluation metrics for developing B-cell epitope prediction tools. Journal of Molecular Recognition. 2007; 20(2):75-82. [DOI:10.1002/jmr.815] [PMID]

[10] Haupt K. Biomaterials: Plastic antibodies. Nature Materials. 2010; 9(8):612-4. [DOI:10.1038/nmat2818] [PMID]

[11] Jarząb A, Skowicki M, Witkowska D. [Subunit vaccines-antigens, carriers, conjugation methods and the role of adjuvants (Polish)]. Postepy higieny i medycyny doswiadczalnej. 2013; 67:1128-43. [DOI:10.5604/17322693.1077807] [PMID]

[12] Kalendar R, Khassenov B, Ramankulov Y, Samuilova O, Ivanov KI. FastPCR: An in silico tool for fast primer and probe design and advanced sequence analysis. Genomics. 2017 109(3-4):312-9. [DOI:10.1016/j.ygeno.2017.05.005] [PMID]

[13] Karfa P, Roy E, Patra S, Kumar D, Madhuri R, Sharma PK. 2016. RETRACTED: A fluorescent molecularly-imprinted polymer gate with temperature and $\mathrm{pH}$ as inputs for detection of alpha-fetoprotein. Biosens Bioelectron. 2016; 78:454-63. [DOI:10.1016/j.bios.2015.11.092] [PMID]

[14] Singh KP, Verma N, Akhoon BA, Bhatt V, Gupta SK, Gupta SK, et al. Sequence-based approach for rapid identification of cross-clade CD8+ T-cell vaccine candidates from all high-risk HPV strains. 3 Biotech. 2016; 6(1):39. [DOI:10.1007/s13205015-0352-z] [PMID] [PMCID]

[15] Larsen JE, Lund O, Nielsen M. Improved method for predicting linear B-cell epitopes. Immunome Research. 2006; 2:2. [DOI:10.1186/1745-7580-2-2] [PMID] [PMCID]

[16] Lesk AM. Introduction to bioinformatics. New York: Oxford University Press; 2002.

[17] Lin CY, Tai DF, Wu TZ. Discrimination of peptides by using a molecularly imprinted piezoelectric biosensor. Chemistry. 2003; 9(20):5107-10. [DOI:10.1002/chem.200304952] [PMID]

[18] Yasser EM, Dobbs D, Honavar VG. In silico prediction of linear B-cell epitopes on proteins. In: Zhou Y, Kloczkowski A, Faraggi E, Yang Y, editors. Prediction of Protein Secondary
Structure. New York: Humana Press; 2017. [DOI:10.1007/9781-4939-6406-2_17] [PMID]

[19] Moreira FT, Ferreira MJ, Puga JR, Sales MG. Screen-printed electrode produced by printed-circuit board technology. Application to cancer biomarker detection by means of plastic antibody as sensing material. Sensors and Actuators B: Chemical. 2016; 223:927-35. [DOI:10.1016/j.snb.2015.09.157] [PMID] [PMCID]

[20] Olson JK, Croxford JL, Calenoff MA, Dal Canto MC, Miller SD. A virus-induced molecular mimicry model of multiple sclerosis. The Journal of Clinical Investigation. 2001; 108(2):311-8. [DOI:10.1172/JCI13032] [PMID] [PMCID]

[21] Saha S, Raghava GP. Prediction of continuous B-cell epitopes in an antigen using recurrent neural network. Proteins: Structure, Function, and Bioinformatics. 2006; 65(1):408. [DOI:10.1002/prot.21078] [PMID]

[22] Singh SP, Srivastava D, Mishra BN. Genome-wide identification of novel vaccine candidates for Plasmodium falciparum malaria using integrative bioinformatics approaches. 3 Biotech. 2017; 7(5):318. [DOI:10.1007/s13205-017-0947-7] [PMID] [PMCID]

[23] Song J, He QF. Bioinformatics analysis of the structure and linear B-cell epitopes of aquaporin-3 from Schistosoma japonicum. Asian Pacific Journal of Tropical Medicine. 2012; 5(2):107-9. [DOI:10.1016/S1995-7645(12)60005-4]

[24] Soria-Guerra RE, Nieto-Gomez R, Govea-Alonso DO, Rosales-Mendoza S. An overview of bioinformatics tools for epitope prediction: Implications on vaccine development. Journal of Biomedical Informatics. 2015; 53:405-14 [DOI:10.1016/j.jbi.2014.11.003] [PMID]

[25] Sun P, Ju H, Liu Z, Ning Q, Zhang J, Zhao X, et al. Bioinformatics resources and tools for conformational B-cell epitope prediction. Computational and Mathematical Methods in Medicine. 2013; 2013(943636):1-11. [DOI:10.1155/2013/943636] [PMID] [PMCID]

[26] Tai DF, Lin CY, Wu TZ, Chen LK. Recognition of dengue virus protein using epitope-mediated molecularly imprinted film. Analytical Chemistry. 2005; 77(16):5140-3. [DOI:10.1021/ ac0504060] [PMID]

[27] Tonevitsky A, Agapov I, Chelnokova O, Moisenovich M, Marx U. Comparison between the mechanisms of action of plant toxins ricin and viscumin on the stage of intracellular dissociation. Arzneimittelforschung. 2002; 52(06):500-5. [DOI:10.1055/s-0031-1299922] [PMID]

[28] World Health Organization. World Bank. State of the world's vaccines and immunization, Geneva: World Health Organization; 2009.

[29] Yao B, Zheng D, Liang S, Zhang C. Conformational B-cell epitope prediction on antigen protein structures: A review of current algorithms and comparison with common binding site prediction methods. PLOS One. 2013; 8(4):e62249. [DOI:10.1371/journal.pone.0062249] [PMID] [PMCID]

[30] Zhao XL, Li DY, He XW, Li WY, Zhang YK. An epitope imprinting method on the surface of magnetic nanoparticles for specific recognition of bovine serum album. Journal of Materials Chemistry B. 2014; 2(43):7575-82. [DOI:10.1039/C4TB01381F] 